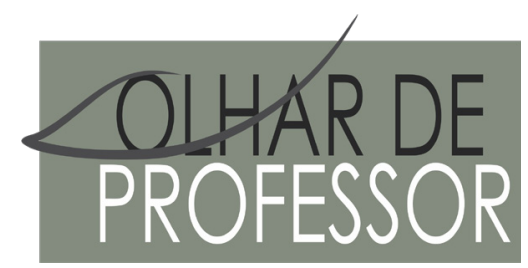

DOI: 10.5212/OLHARPROFR.v23.2020.15649.209209225856.0601

\title{
ENEM DURANTE A PANDEMIA? UM ESTUDO DE CASO DAS PERCEPÇÕES DE DOCENTES DA REDE ESTADUAL DE EDUCAÇÃO DO RIO DE JANEIRO SOBRE A REALIZAÇÃO DO ENEM 2020
}

\author{
ENEM DURING PANDEMIC? A STUDY OF RIO DE JANEIRO STATE TEACHERS' PERCEPTIONS ON THE \\ REALIZATION OF ENEM 2020
}

\section{ENEM DURANTE LA PANDEMIA? UN ESTUDIO DE CASO DE LAS PERCEPCIONES DE LOS DOCENTES DE LA RED DE EDUCACIÓN DEL ESTADO DE RÍO DE JANEIRO SOBRE LA REALIZACIÓN DE ENEM 2020}

\author{
REGINA LUCIA FERNANDES DE ALBUQUERQUE*
}

\begin{abstract}
Resumo: Tem-se por objetivo mapear as percepções de professores da Rede Estadual de Educação do Rio de Janeiro sobre a realização do Exame Nacional do Ensino Médio (ENEM), assim como analisar o oferecimento de atividades pedagógicas não presenciais aos alunos da rede que prestariam o exame. Trata-se de estudo exploratório, com 22 professores atuantes em turmas de Ensino Médio. A coleta de dados foi realizada através de aplicação de questionário remoto, com formato semiestruturado. Os resultados parciais apontaram para divergências entre os professores em relação à realização do ENEM 2020, incluindo docentes que declararam percepções distintas quanto à realização do exame, utilizando-se de justificativas similares.
\end{abstract}

Palavras chave: Covid-19. Ensino Médio. ENEM 2020.

\begin{abstract}
The objective is to map the teacher's perceptions of the State Education of Rio de Janeiro about the ENEM 2020's realization, as well as to analyze the provision of non-classroom pedagogical activities to students that would take the exam. This is an exploratory study, with 22 teachers working in high school classes. Data collection was performed through the application of a remote questionnaire, with a semi-structured format. The partial results pointed to divergences among teachers about the realization of ENEM 2020, including teachers who declared different perceptions regarding the realization of the test, using similar justifications.
\end{abstract}

Keywords: Covid-19. High School. ENEM 2020.

Resumen: El objetivo es mapear las percepciones de los docentes de la Red de Educación del Estado de Río de Janeiro sobre la realización de ENEM 2020, así como analizar la provisión de actividades pedagógicas fuera del aula para los estudiantes de la red que tomarían el examen. Este es un estudio exploratorio, con 22 maestros trabajando en clases de secundaria. La recolección de datos se realizó mediante la aplicación de un cuestionario remoto, con una estructura de respuestas semiestructuradas. Los resultados parciales apuntaban a divergencias entre los docentes sobre la realización de ENEM 2020, incluidos los docentes que declararon diferentes percepciones con respecto a la realización de la prueba, utilizando justificaciones similares.

Palabras clave: Covid-19. Escuela secundaria. ENEM 2020.

\footnotetext{
* Doutoranda pelo Programa de Pós graduação em Educação da Universidade Federal de Minas Gerais (PPGE-UFMG). Mestre em Educação pela Universidade Federal do Rio de Janeiro (PPGE-UFRJ). Professora da Rede Estadual de Educação do Rio de Janeiro. E-mail: albuquerquerlf@gmail.com
} 


\section{INTRODUÇÃO}

A Organização Mundial de Saúde (OMS) reportou, em 31 de dezembro de 2019, uma epidemia de síndrome respiratória aguda grave em Wuhan, província de Hubei, na China. O surto foi declarado como Emergência de Saúde Pública de Importância Internacional em 30 de janeiro de $2020^{1}$. No Brasil, a partir de março de 2020, frente à confirmação de óbitos por síndrome respiratória aguda grave (SARSCoV-2/Covid-19), os governadores de distintas Unidades da Federação iniciaram medidas de restrição da mobilidade urbana. Suspendendo ou substituindo, por acesso remoto, serviços de atendimento ao público.

Frente à reorganização da oferta de serviços em decorrência das medidas de isolamento, impõe-se a questão da garantia do acesso à educação. Contudo, é preciso questionar a universalidade dos métodos aplicados com vistas a essa garantia. Pesquisas apontam que características secundárias entre grupos de alunos possuiriam uma forte correlação com seu desempenho, como, por exemplo, o nível socioeconômico familiar, escolaridade materna, gênero e raça de pertencimento do aluno (ÉRNICA; SETUBAL, 2019). De acordo com o Observatório Social da Covid-19, 17 milhões de residências nacionais (20\% do total de residências brasileiras), não possuem acesso à internet. Nestes domicílios, residem 7 milhões de estudantes, dos quais 95\% estão matriculados em escolas públicas. Dessa maneira, a oferta de atividades pedagógicas não presenciais por acesso remoto durante o período da pandemia pela Covid-19, pode vir a se caracterizar como mais uma variável que se associa ao fenômeno da desigualdade educacional.

Para os estudantes do final do Ensino Médio que almejam a entrada na universidade pública, o acesso aos recursos e equipamentos para estudo remoto pode vir a ser uma variável fortemente relacionada ao seu desempenho nos exames de acesso ao Ensino Superior. Dessa maneira, a pesquisa tem por objetivo mapear as percepções de professores da Rede Estadual de Educação do Rio de Janeiro sobre a realização do ENEM 2020, assim como analisar o oferecimento de atividades pedagógicas não presenciais aos alunos da rede que prestariam o exame.

A realização da pesquisa justifica-se pela contribuição ao campo de estudos em educação que intenciona compreender a oferta educacional e seus desdobramentos durante a pandemia pela Covid-19 no Brasil. A metodologia empreendida foi caracterizada por estudo exploratório, contando com vinte e dois professores atuantes em turmas de Ensino Médio, na Rede Estadual de Educação do Rio de Janeiro. A coleta de dados foi realizada através de aplicação de questionário remoto, com formato semiestruturado. O quantitativo de participantes não pode ser considerado um percentual estatístico representativo dos profissionais da Rede de Educação Estadual do Rio de Janeiro. Uma vez que, seria preciso um percentual acima de $60 \%$ do total de professores da rede para a amostra ser considerada estatisticamente significativa. Este não é o intuito da pesquisa que é caracterizada como estudo exploratório. Os resultados aqui apresentados são tomados como indícios e sugerem-se posteriores investigações sobre o tema.

Dessa maneira, o texto divide-se em quatro partes: a primeira comporta breve apresentação sobre o ENEM e seu potencial de ampliação dos grupos que acessam o Ensino Superior no Brasil. A segunda apresenta análise documental das normatizações sobre a oferta de atividades pedagógicas não presenciais pelo Governo Federal, Ministério da Educação (MEC) e Conselho Nacional de Educação (CNE). Já o terceiro momento abarca a discussão dos dados coletados nas entrevistas com professores. O texto encerra-se com as considerações finais.

\section{O ENEM: BREVE APRESENTAÇ̃̃O}

Criado em 1998, o Exame Nacional do Ensino Médio (ENEM) suscita discussões sobre sua relação com a ampliação das características dos grupos sociais que ingressam no Ensino Superior. Se, por um lado, há críticas ao ENEM como um exame que promove a exclusão das parcelas mais vulneráveis da população de jovens no acesso ao Ensino Superior; por outro lado, as políticas públicas de ações afirmativas para esse acesso se refletiriam em uma ampliação- embora pouco generalizada e estratificada

\footnotetext{
${ }^{1}$ Fonte: Organização Pan-americana da Saúde. Disponível em: https://www.paho.org/bra/index.php?option=com_content\&vi ew=article\&id=6101: covid19\&Itemid=875. Acesso em: 03/05/2020.
} 
pelos cursos segundo a nota de corte- das características secundárias dos grupos sociais que acessam o Ensino Superior.

A partir de 2009, o ENEM foi reformulado e ampliado ${ }^{2}$ com a implementação do Sistema de Seleção Unificado (SISU), nacionalizando a disputa pelas vagas. Com a Lei $12.711^{3}$, de 29 de agosto de 2012, edifica-se a política pública de ação reparatória com a reserva de vagas aos alunos de escolas públicas, com renda per capita familiar de até um salário mínimo e meio, autodeclarados pretos, pardos ou indígenas e pessoas com deficiência. Caracterizando-se como ação que visa a redução de desigualdade de acesso desses grupos à continuidade de sua escolarização.

Considerando que o ENEM é uma das principais ferramentas para o acesso ao Ensino Superior, a relação entre o debate sobre o cronograma de realização do ENEM 2020 e a suspensão das atividades pedagógicas presenciais com a pandemia da Covid-19, coloca à prova as políticas de ação reparatória. Dessa maneira, faz-se necessário compreender as formas de organização e oferta das atividades pedagógicas não presenciais no período da pandemia pela Covid-19, sobretudo para os alunos de escolas públicas. A seguir, apresenta-se levantamento das normatizações nacionais sobre a oferta de atividades pedagógicas não presenciais.

\section{MARCOS REGULADORES DA OFERTA DE ATIVIDADES PEDAGÓGICAS NÃO PRESENCIAIS.}

Através da Portaria n ${ }^{0}$ 376, de 03 de abril de 2020, o MEC autorizou a suspensão das aulas presenciais e/ou sua substituição por atividades não presenciais para as modalidades de Ensino Profissional Técnico e Ensino Médio, pelo prazo de sessenta dias. O artigo segundo da portaria, estabeleceu reposição de carga horária integral do período suspenso às instituições que não aderissem ao oferecimento de aulas remotas ${ }^{4}$. Já para as instituições que aderissem ao acesso remoto, a Portaria ${ }^{0} 376$ regulamentou que a oferta deveria ser mediada por recursos digitais ou que fosse disponibilizado aos estudantes materiais de apoio e orientações que permitissem a continuidade dos estudos.

Em 28 de abril, de 2020, o CNE votou o documento "Proposta de Parecer sobre Reorganização dos Calendários Escolares e Realização de Atividades Pedagógicas não Presenciais durante o Período de Pandemia da COVID-19”. O documento indicou como formas de oferta de atividades pedagógicas não presenciais: atividades na modalidade Ensino à Distância $(\mathrm{EaD})$ - videoaulas, conteúdos organizados em plataformas virtuais de ensino-aprendizagem, redes sociais, correio eletrônico, blogs, entre outros-; transmissão de aulas por programas de televisão ou rádio; distribuição de material didático impresso com orientações de leituras, projetos, pesquisas, atividades e exercícios.

Em relação à oferta educacional aos alunos especiais, o documento do CNE sinalizou a garantia do Atendimento Educacional Especializado (AEE), com atuação do profissional AEE na adequação dos materiais disponibilizados por acesso remoto e em articulação com as famílias dos alunos. No entanto, o documento não apresentou detalhamento procedimental para atuação do profissional AEE. Já em relação ao atendimento pelas instituições educacionais localizadas em territórios de povos tradicionais como quilombolas e indígenas, o documento preconizou pela parcial oferta de atividades presenciais, com encaminhamento de estudos dirigidos a serem realizados pelos alunos em suas residências.

O CNE ainda orientou ao MEC e ao Instituto Nacional de Estudos e Pesquisas Educacionais Anísio Teixeira (INEP), que acompanhem as ações descentralizadas nos estados, aguardando o retorno às aulas para definição de cronograma e especificidades do ENEM. Contrariando as recomendações do CNE,

\footnotetext{
${ }^{2}$ Desde 2004 já vigorava o Programa Universidade para Todos (ProUni), que também ampliou o acesso ao Ensino Superior, embora no setor privado, através da concessão de bolsas aos estudantes que comprovassem renda per capita familiar de até um salário mínimo e meio.

${ }^{3}$ A Lei 12.711 institui a reserva de 50\% das vagas das instituições de Ensino Superior vinculadas ao Ministério da Educação para estudantes que tenham cursado integralmente o Ensino Médio em escolas públicas, Desse percentual, 50\% será reservado aos alunos com renda familiar per capita de um salário mínimo e meio. Sendo essas vagas preenchidas, em cada instituição de ensino, por curso e turno, por autodeclarados pretos, pardos, indígenas e por pessoas com deficiência. Segundo a proporção desses grupos na população da Unidade da Federação na qual se encontra a instituição de ensino.

${ }^{4}$ Em acordo com a Medida Provisória no 934, de 01 de abril de 2020.
} 
o MEC, através do INEP, publica o edital $n^{\circ} 25$, de 30 de março de 2020, definindo o cronograma do ENEM 2020, prevendo a aplicação das avaliações nas datas de 01 e 08 de novembro. A manutenção do calendário do ENEM, ignorando a grande dificuldade das redes de ensino de promoverem a manutenção do contato dos alunos com os conteúdos lecionados, sobretudo na rede pública onde se concentra o maior percentual de alunos de baixo perfil socioeconômico, suscitou reações das instituições de ensino. Em nota conjunta, diversas instituições públicas de educação do Rio de Janeiro manifestaram-se pelo adiamento do ENEM, apontando que a manutenção de seu calendário ampliaria as desigualdades de acesso ao Ensino Superior (NOTA CONJUNTA, 2020). A pressão das instituições levou o Senado Federal a se manifestar em votação ao PL 1.277/2020, aprovando, em 19 de maio de 2020, o adiamento do ENEM. Após a votação no Senado Federal, o INEP anunciou o adiamento de trinta a sessenta dias do cronograma de aplicação das provas do ENEM 2020.

A seguir, analisam-se os dados do estudo exploratório empreendido com docentes da Rede Estadual de Educação do Rio de Janeiro.

\section{RESULTADOS}

O perfil dos entrevistados contou tanto com professores atuantes na rede há oito meses, quanto com aqueles que lecionam há vinte e seis anos nas escolas da Secretaria Estadual de Educação do Rio de Janeiro. Essa mesma amplitude foi observada em relação às disciplinas ministradas pelos entrevistados, abrangendo História, Sociologia, Biologia, Língua Portuguesa, Filosofia, Química, Geografia e Artes. A localização das escolas em que os docentes trabalham englobou desde a capital do Rio de Janeiro e região Metropolitana (Niterói e São Gonçalo), até municípios da Zona Oeste e interior (Japeri, Miguel Pereira e Vera Cruz) e Baixada Litorânea (Angra dos Reis). Vinte e um dos entrevistados declararam que a(s) escola(s) que lecionam atendem público de baixo perfil socioeconômico. Um dos entrevistados afirmou que a escola em que leciona atenderia público com perfil socioeconômico "misto".

Em relação à avaliação sobre a adesão estudantil às atividades pedagógicas não presenciais por acesso remoto, um professor avaliou que a adesão dos alunos foi boa e vinte e um avaliaram que a adesão foi baixa. Como possível justificativa para baixa adesão pelos alunos, foram citadas dificuldades de condições de acesso aos recursos necessários para utilização da plataforma. O mesmo panorama repete-se em relação à avaliação do acesso por alunos especiais.

Em relação a avaliação dos possíveis impactos na aprendizagem dos alunos, vinte professores acreditam que esse período acarretará em um déficit na aprendizagem e dois professores acreditam que esse período pode agregar à aprendizagem dos estudantes. Enquanto possíveis soluções para atenuar o impacto negativo na aprendizagem, foram citados: reorganização do calendário letivo de 2020, elaboração de atividades com propostas que contemplem a dimensão da ludicidade, realização de avaliação diagnóstica quando do retorno das aulas presenciais e reforço escolar com o grupo de alunos que apresentarem maior déficit em relação ao conteúdo.

Quando questionados se possuiriam opinião sobre a realização do ENEM 2020 e, em caso positivo, a avaliação que possuiriam sobre o cronograma do exame, três professores não opinaram ou não souberam responder, quatro professores acreditam que o ENEM deve ser suspenso, cinco acreditam que o ENEM 2020 deve ser cancelado e dez professores acreditam que o ENEM 2020 deve ser adiado. Das questões formuladas, essa pareceu ser a que apresentou maior dispersão entre as respostas, incluindo justificativas similares para aqueles que opinaram de maneira distinta.

O ENEM de 2020 deve ter sua realização adiada para que todos os estudantes concluintes desse ano letivo tenham condições menos desiguais para a sua realização, já que o ENEM serve de concurso de acesso ao Ensino Superior em diversas instituições. (Professor 14).

Penso que o ENEM 2020 deveria ser cancelado. Se mantido, só demonstra que o acesso a Universidade pública está para os filhos da classe média branca que tem acesso a tudo. ENEM só quando terminasse a Covid ou quando já existisse uma vacina. (Professor 21).

A seguir, o texto encerra-se com as considerações finais. 


\section{CONSIDERAÇÕES FINAIS}

É possível perceber um atraso das publicações do Governo Federal, MEC e CNE em relação às orientações tanto sobre a suspensão das aulas presenciais, quanto sobre a oferta de atividades pedagógicas não presenciais por acesso remoto. O governo do estado do Rio de Janeiro suspendeu as aulas presenciais em 13 de março de 2020, através do Decreto n46.970. Contudo, o MEC só autorizaria essa suspensão e/ou sua substituição por atividades não presenciais, em 03 de abril de 2020, através da Portaria $\mathrm{n}^{\circ}$ 376. Observa-se, tanto em relação ao prazo de resposta, quanto ao volume de decretos de normatizações, que as ações reguladoras da oferta educacional durante a primeira onda da Covid-19 no país, caracterizaram-se pela descentralização.

O documento do CNE, ainda que tenha apontado uma sensibilidade maior do que a do MEC e do Governo Federal para a oferta e acesso das atividades pedagógicas não presenciais, realizou-o de forma parcimoniosa, desconsiderando tanto características regionais, quanto as características de grupos de alunos com maior vulnerabilidade. Embora, seja o documento mais propositivo dentre aqueles emitidos pelos órgãos da União.

Majoritariamente, os docentes que participaram da pesquisa acreditam que o período de oferta de atividades pedagógicas não presenciais acarretará em um déficit na aprendizagem dos alunos, sobretudo considerando a dificuldade que os estudantes têm apresentado em relação à disponibilidade de recursos e aparelhos para o acesso remoto.

Em relação à realização do ENEM 2020, apesar da maioria dos entrevistados apontarem que o exame deveria ser adiado, foram utilizadas justificativas similares dentre aqueles que declararam que o exame deveria ser adiado e aqueles que acreditam que este deveria ser cancelado. O desafio que se materializa a partir da dificuldade de manutenção do contato dos alunos com o conteúdo comumente exigido no ENEM, é a fragilização das políticas públicas de ação reparatória de acesso desses alunos ao Ensino Superior.

\section{REFERÊNCIAS}

ANPED. Posicionamento sobre o Parecer do CNE que trata da Reorganização dos Calendários Escolares durante a Pandemia. Rio de Janeiro: Portal ANPED, 24/04/2020. Disponível em: http:// www.anped.org.br/news/posicionamento-sobre-o-parecer-do-cne-que-trata-da-reorganizacao-doscalendarios-escolares. Acesso em: 05/05/2020.

BRASIL. Lei No 12.711, de 20 de agosto de 2012. Diário Oficial da República Federativa do Brasil, Poder executivo, Brasília, DF, agosto de 2012. Disponível em: http://www.planalto.gov.br/ccivil_03/_ Ato2011-2014/2012/Lei/L12711.htm. Acesso em: 31/05/2020.

BRASIL. Medida Provisória No 934, de 1 de abril de 2020. Diário Oficial da República Federativa do Brasil, Poder executivo, Brasília, DF, abril de 2020. Disponível em: http:/www.in.gov.br/en/web/ dou/-/medida-provisoria-n-934-de-1-de-abril-de-2020-250710591. Acesso em: 29/04/2020.

BRASIL. Projeto de Lei 1.277 de 2020. Diário Oficial da República Federativa do Brasil, Senado Federal, Brasília, DF, 20/05/2020. Disponível em: https://www25.senado.leg.br/web/atividade/ materias/-/materia/141354. Acesso em 20/05/2020.

DIÁRIO OFICIAL DO ESTADO DO RIO DE JANEIRO. Decreto No 46.970, de 13 de março, de 2020. Rio de Janeiro, ano XLVI, no 047-A, 13 de março de 2020, p 1.. Disponível em: https://www. jusbrasil.com.br/diarios/DOERJ/2020/03/13. Acesso em: 25/04/2020.

ERNICA, Maurício; SETUBAL, M. A. IDEA: indicador de desigualdades e aprendizagens. In: Revista Periferias, v 2, p.1-10, 2019. Disponível em: http://revistaperiferias.org/materia/idea-odireito-de-todos-a-educacao-de-qualidade/?pdf=2316. Acesso em: 07/04/2020.

ESTADO DE MINAS GERAIS. Domicílios sem internet sofrem os impactos do isolamento social. Entrevista concedida por Jorge Alexandre Neves, professor titular do Departamento de Sociologia 
da Universidade Federal de Minas Gerais. Estado de Minas Gerais, Minas Gerais, 12 de abril de 2020. Disponível em: https://www.em.com.br/app/noticia/gerais/2020/04/12/interna_gerais,1137796/ domicilios-sem-internet-sofrem-os-impactos-do-isolamento-social.shtml. Acesso em: 06/05/2020.

INEP. Nota Oficial adiamento do ENEM 2020. Ministério da Educação, Instituto Nacional de Estudos e Pesquisas Educacionais Anísio Teixeira, Brasília, DF, 20 de maio de 2020. Disponível em: http://portal.inep.gov.br/artigo/-/asset_publisher/B4AQV9zFY7Bv/content/ id/6877584?fbclid=IwAR0mrIBOCdgrhaxQ9tBLph2swHpGtb7JIMDhqJF090KDFaUjViZhATZIOz0. Acesso em: 20/05/2020.

MINISTÉRIO DA EDUCAÇÃO, CONSELHO NACIONAL DE EDUCAÇÃO. Proposta de Parecer sobre Reorganização dos Calendários Escolares e Realização de Atividades Pedagógicas não Presenciais durante o Período de Pandemia da COVID-19. Ministério da Educação, Conselho Nacional de Educação, 28 de abril de 2020. Disponível em: http://portal.mec.gov.br/index. php?option=com_docman\&view=download\&alias=144511-texto-referencia-reorganizacao-doscalendarios-escolares-pandemia-da-covid-19\&category_slug=marco-2020-pdf\&Itemid=30192. Acesso em: 30/04/2020.

MINISTÉRIO DA EDUCAÇÃO. Portaria No 376, de 03 de abril de 2020. Ministério da Educação, Brasília: DF. Disponível em: https://abmes.org.br/arquivos/legislacoes/Portaria-mec-376-2020-04-03. pdf. Acesso em: 03/05/2020.

MINISTÉRIO DA EDUCAÇÃO. Edital Nº 25, de 30 de março de 2020. Ministério da Educação. Brasília, DF. Edição 62, seção 3, página 33. Disponível em: http://www.in.gov.br/web/dou/-/editaln-25-de-30-de-marco-de-2020exame-nacional-do-ensino-medio-enem-2020-impresso-250463829. Acesso em: 15/05/2020.

NOTA CONJUNTA. O Enem deve ser adiado. Assinada por: reitoria UFF, reitoria UFRJ, reitoria IFF, reitoria CEFET, reitoria UEZO, reitoria Colégio Pedro II, reitoria IFRJ, reitoria UENF, reitoria UFRRJ, reitoria UERJ, reitoria UNIRIO. Portal Colégio Pedro II. Rio de Janeiro, maio de 2020. Disponível em: https://drive.google.com/file/d/10E8zXQgg3CoIIClZ2lRzl2f_DyQA5Atb/view. Acesso em: 15/05/2020. 